\title{
Review Article \\ Friction Stir Spot Welding: A Review on Joint Macro- and Microstructure, Property, and Process Modelling
}

\author{
X. W. Yang, ${ }^{1}$ T. Fu, ${ }^{1}$ and W. Y. Li ${ }^{1,2}$ \\ ${ }^{1}$ State Key Laboratory of Solidification Processing, Shaanxi Key Laboratory of Friction Welding Technologies, \\ Northwestern Polytechnical University, Xian 710072, China \\ ${ }^{2}$ School of Materials Science and Engineering, Northwestern Polytechnical University, Xian 710072, China
}

Correspondence should be addressed to W. Y. Li; liwy@nwpu.edu.cn

Received 7 March 2014; Accepted 23 April 2014; Published 25 June 2014

Academic Editor: Achilleas Vairis

Copyright ( $\odot 2014$ X. W. Yang et al. This is an open access article distributed under the Creative Commons Attribution License, which permits unrestricted use, distribution, and reproduction in any medium, provided the original work is properly cited.

\begin{abstract}
Friction stir spot welding (FSSW) is a very useful variant of the conventional friction stir welding (FSW), which shows great potential to be a replacement of single-point joining processes like resistance spot welding and riveting. There have been many reports and some industrial applications about FSSW. Based on the open literatures, the process features and variants, macro- and microstructural characteristics, and mechanical properties of the resultant joints and numerical simulations of the FSSW process were summarized. In addition, some applications of FSSW in aerospace, aviation, and automobile industries were also reviewed. Finally, the current problems and issues that existed in FSSW were indicated.
\end{abstract}

\section{Introduction}

Recently, lightweight metals such as aluminium alloys are increasingly used, especially in aerospace and automotive industries, where weight saving is extremely important [1]. Resistance spot welding, laser spot welding, and riveting have been widely used for aluminium alloys sheet assemblies. However, the conventional resistance spot welding has disadvantages such as consumption of tool during joining, large heat distortion, and poor weld strength in joints; porosity defects cannot be avoided by laser spot welding; riveting will increase the weight of components and the drilling needed will increase the cost [2]. Hence, new spot welding processes are required for joining parts made of aluminium alloys.

Friction stir welding (FSW) was developed by TWI in $1991[3,4]$. It offers various advantages such as small thermal deformation, sound mechanical properties, fine and uniform weld microstructure, high welding efficiency, and green welding process, which has received considerable attention in welding aluminium alloys [5-7]. As FSW is developed, studies on FSW of other advanced materials, such as magnesium alloys, copper alloys, titanium alloys, steels, and superalloys, have been reported.
As a variant of FSW, friction stir spot welding (FSSW) has been proposed to realise a spot weld. It shows great potential to be a replacement of single-point joining processes like resistance spot welding and riveting, and it has wider applications in aerospace, aviation, and automobile fields [7]. Up to now, there are many reports about FSSW, which mainly focus on the process, microstructural characteristics, mechanical properties, and numerical simulations. This review will summarise these aspects about FSSW.

\section{The Processes of FSSW}

Conventional FSSW was invented by Mazda Motor Corporation in 1993 [8], which is similar in concept and appearance to its predecessor FSW. As shown in Figure 1, the FSSW process consists of three stages: plunging, stirring, and retracting [9]. The process starts with the tool rotating at a high angular speed. Then the tool is forced into workpieces until the tool shoulder contacts the top surface of the upper workpiece to form a weld spot. The plunging movement of the tool causes the expelling of materials. After plunging, the stirring stage starts when the tool reaches a predetermined depth. In this stage, the tool keeps rotating in the workpieces. Frictional 


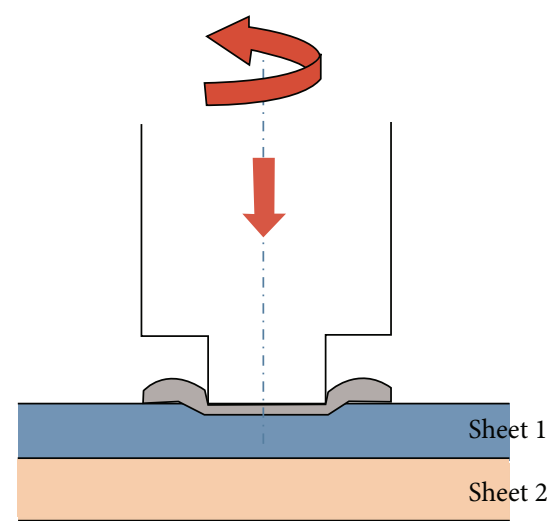

(a)

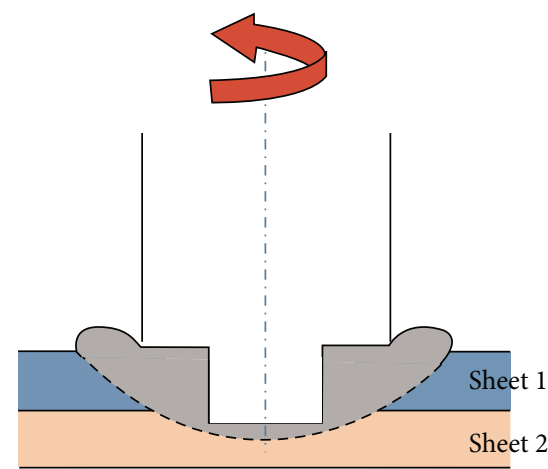

(b)

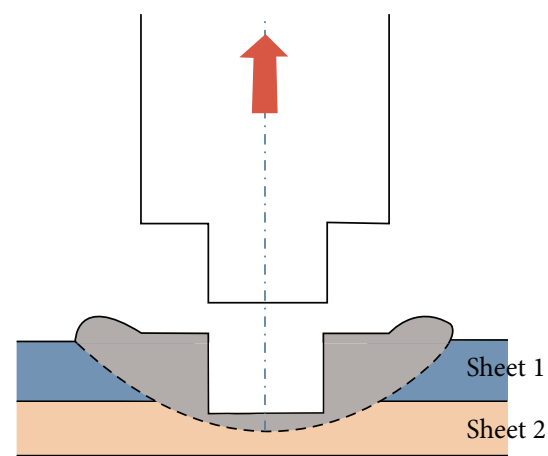

(c)

FIGURE 1: Illustration of the FSSW process: (a) plunging, (b) stirring, and (c) retracting [9].

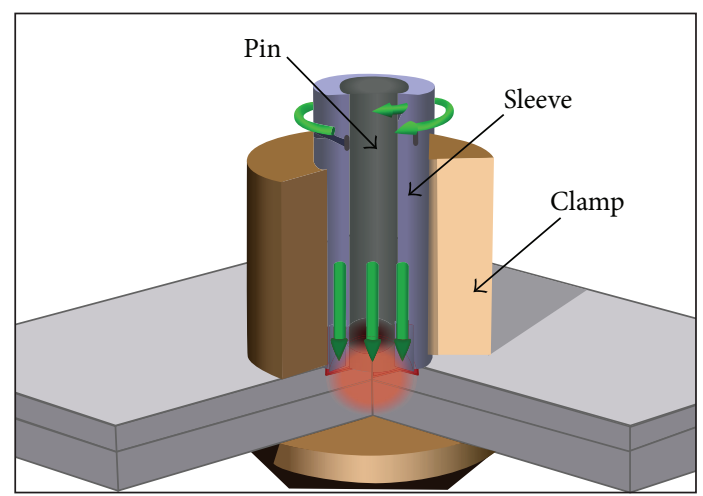

(a)

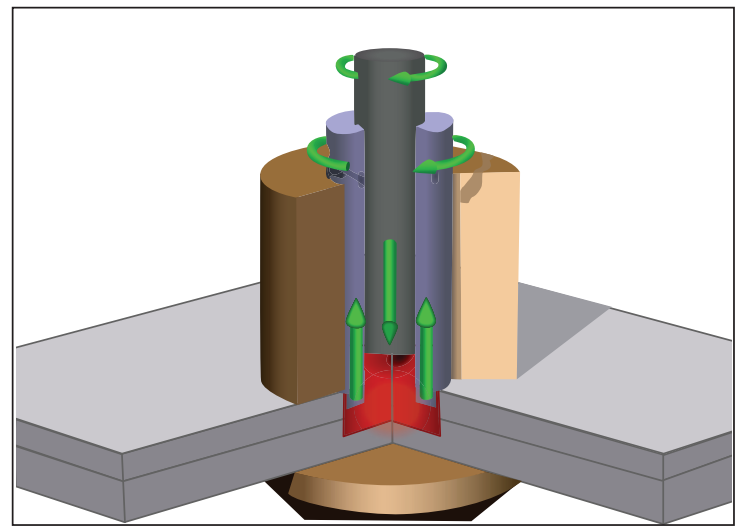

(c)

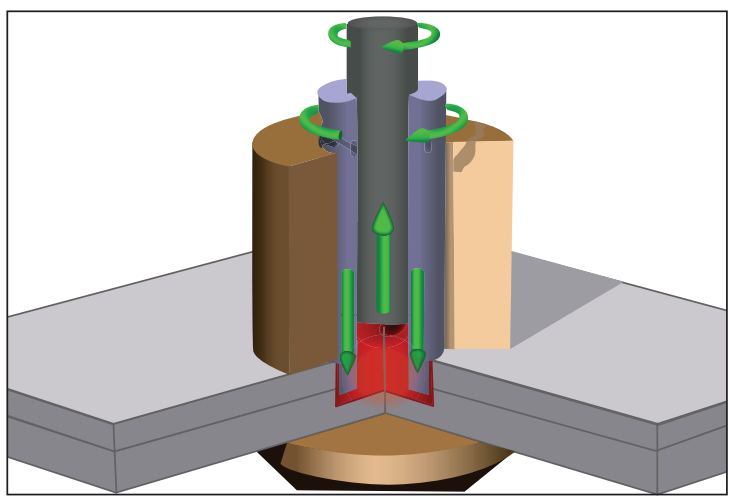

(b)

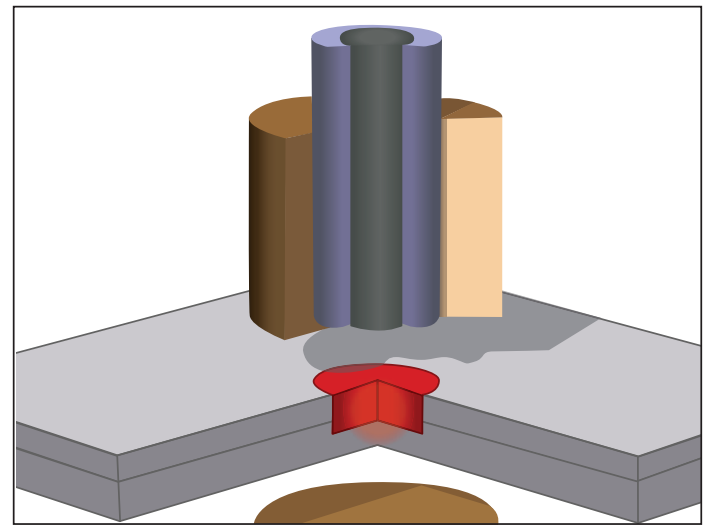

(d)

FIGURE 2: Schematic diagram of the refill FSSW process: (a) friction, (b) first extrusion, (c) second extrusion, and (d) pull-out stage [11].

heat is generated in the plunging and stirring stages, and thus the materials adjacent to the tool are heated, softened, and mixed in the stirring stage where a solid-state joint will be formed. When an acceptable bonding is obtained, the tool is retracted from the workpieces. This joint has a characteristic keyhole in the middle, which significantly decreases the mechanical properties of the joints [9].
In order to eliminate the keyhole or increase the strength of joints, several processes have been proposed, such as the refill FSSW, pinless FSSW, and swing FSSW [8].

2.1. The Refill FSSW. The refill FSSW was developed and patented by Helmholtz-Zentrum Geesthacht, Germany [10]. As shown in Figure 2, the refill FSSW process consists of four 


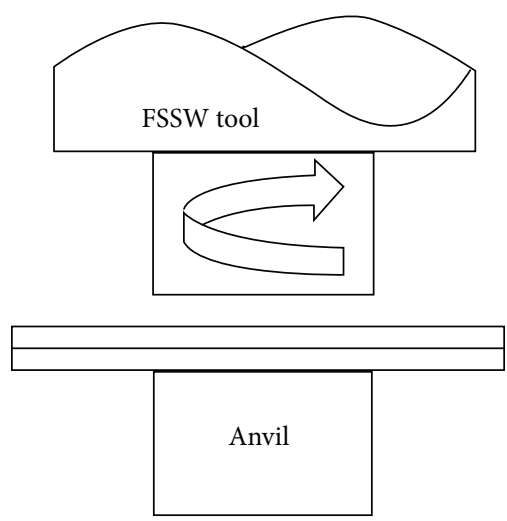

(a)

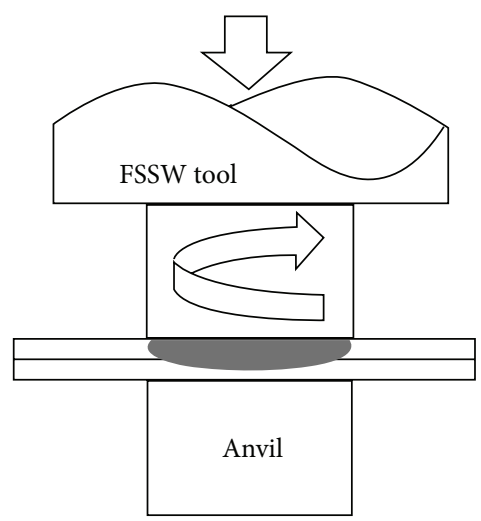

(b)

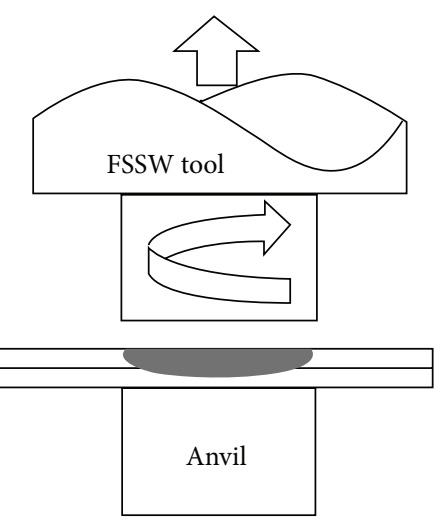

(c)

FIGURE 3: Illustration of the pinless FSSW process: (a) plunging, (b) stirring, and (c) retracting [12].
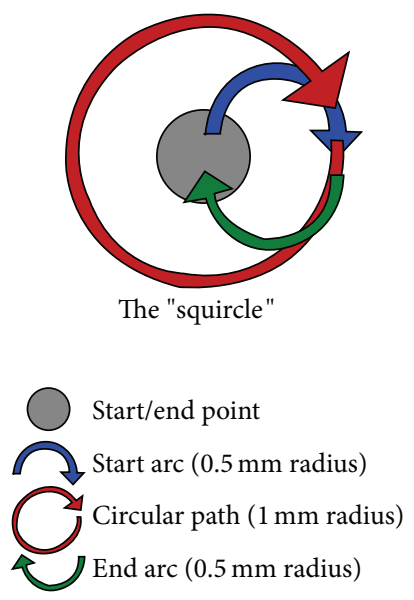

FIGURE 4: Illustration of weld path of swing FSSW [14].

phases: friction, first extrusion, second extrusion, and pullout. In this process, the tool has three parts: pin, sleeve, and clamp. The clamp holds the plates firmly against the anvil and also constrains the material flow during the process. While the pin and sleeve begin to rotate in the same direction, they can translate independently in the axial direction. The pin and sleeve move in the opposite direction (i.e., one is plunged into the material, while the other moves upwards), creating a space where the plasticised material is accommodated. After reaching the preset plunge depth, the pin and sleeve move reversely to the surface of the plate, forcing the displaced material to completely refill the keyhole. Finally, the tool is withdrawn from the joint leaving a flat surface with minimum material loss [11].

There are fewer applications about this process, because of complicated procedures, long dwell time, and high cost. However, the keyhole could be eliminated, and the weld strength is improved.

2.2. The Pinless FSSW. The pinless FSSW was invented by Tazokai. In this process, the tool without a probe but with a scroll groove on its shoulder surface has been proposed in
$2009[1,12]$. This kind of pinless tool has many advantages, a simpler process, and a better appearance with a shallow or no keyhole retained. This process is schematically shown in Figure 3. Recently, preliminary data have shown that this approach can be used to produce high-strength welds with a short dwell time $[12,13]$.

2.3. The Swing FSSW. The swing FSSW was developed by TWI, UK. In this process, the tool moves along a preset path after plunging (Figure 4). This process increases the actual area of weld and the strength of joints [14], while it could not eliminate the keyhole.

2.4. The Other New FSSW Process. To obtain a weld joint without a keyhole, Sun et al. [15-17] used a new FSSW technique. This process includes two steps (Figure 5), in the first step, a specially designed backplate containing a round dent is used for conventional FSSW. After the first step, a keyhole is formed in the joint, along with a protuberance on the lower sheet due to the flow of materials into the dent. In the second step, a pinless tool and a flat backplate are employed to remove both the keyhole and the protuberance successfully. This novel process has been applied in 6061 and 5052 aluminum alloys [16].

\section{Macrostructure and Microstructure of FSSW Joints}

3.1. Macrostructure of FSSW Joints. Wang and Lee [18] investigated macrostructure of friction stir spot welds in aluminum 6061-T6 lap-shear specimens. In their study, keyhole was observed on the top surface of the weld. The thickness of the upper sheet material under the shoulder indentation decreased at the squeezing action of tool, consequently, resulting in an expansion of the upper sheet. However, the sheet was bent along the outer circumference of the shoulder indentation under the constraint of the neighboring material. And it was showed that squeezed out material was accumulated along the outer circumference of the shoulder 


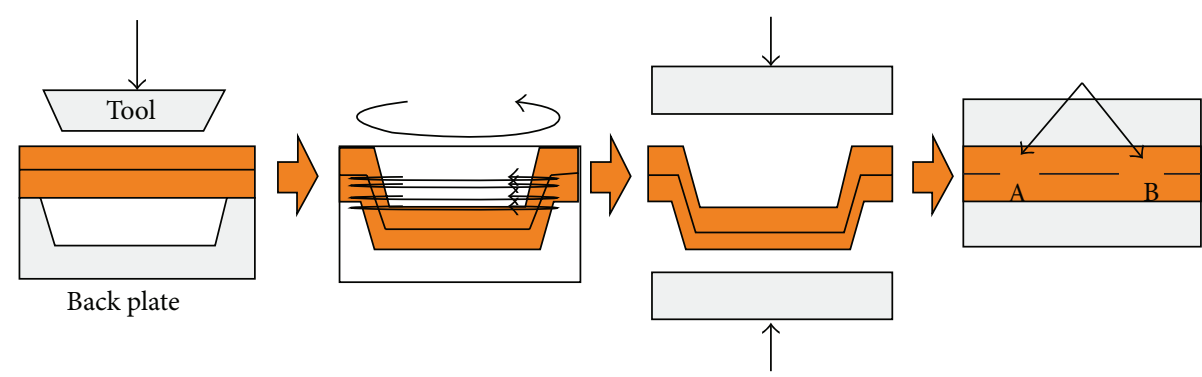

FIGURE 5: Schematic illustration of the novel FSSW [16].

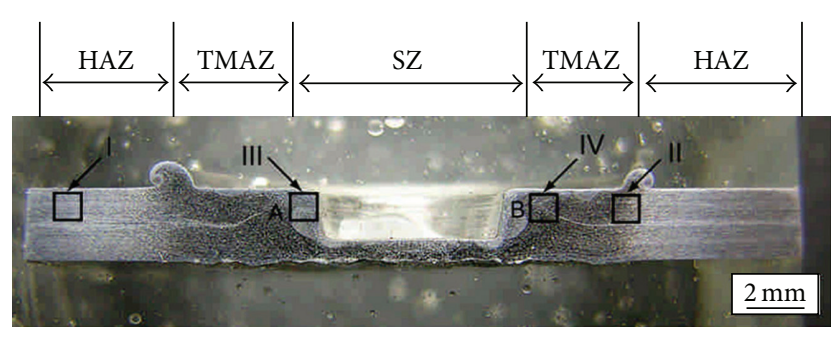

FIGURE 6: A typical micrograph of the cross-section of a friction stir spot weld [18].

indentation. Similar phenomenon was observed in the joints of friction stir spot microwelds [19].

Three distinct regions were revealed in FSSW weld joint: the stir zone (SZ), the thermomechanically affected zone (TMAZ), and heat affected zone (HAZ) [11, 18], and the gray area represented the SZ (Figure 6). For refill FSSW, Uematsu et al. [20] found that weld is classified into three zones: mixed zone (MZ), stir zone (SZ), and parent metal (PM) (Figure 7). In MZ, grains were slightly coarser than those in SZ because the material in this region was stirred more severely than SZ, and there was more heat input into MZ during the refilling process. However, for swing FSSW, Yan et al. [21] showed that weld had three regions: plastic ring region, thermomechanically affected zone, and heat affected zone and parent metal.

Cross-sectional macrostructure of the joints at different dwell time was observed by Fujimoto et al. [22]. When dwell time was $0.4 \mathrm{~s}$, there was stripe pattern caused by plastic deformation in the area adjacent to the pin. At $0.8 \mathrm{~s}$, it was showed that a couple of darkly etched small regions were formed. The region apparently became larger with the increase of tool dwell time. For joints of galvanized steel, white layer was found at the top sheets in all samples. Authors explained it to the phase transformation of galvanized steel or the reaction between the tool and steel sheets [23].

It is known that macroscopic appearance of FSSW joint is influenced by temperature and material plastic deformation. Moreover, welding parameters (mainly include rotation speed, dwell time, plunge depth, and plunge rate) decide the friction heat during welding. Hence, macroscopic appearance changes with the change of welding parameters. Yuan et al. [24] demonstrated that larger bonded region of AA6016-T4 weld could be gained at lower rotation speed. The reason was that heat input increased with the increase of tool rotation speed, which in turn decreased the amount of material into the stir zone. Li et al. [25] reported that plunge depth increased with the increase of dwell time and plunge rate on the pinless friction stir spot welding of AA2024. Similarly, Baek et al. [23] showed that gap at the joint edge region decreased with increasing of tool plunge depth.

Feng et al. [26] have found that interface morphology of joining of an aluminum alloy sheet to a steel sheet changed with the change of melting temperature of the plated layer. In their study, steel sheets were plated by pure zinc (GI), zinc alloy (ZAM), Al-Si alloy (AS), and zinc alloy including Fe (GA). For ZAM and GI, bonding area was achieved in the limited area close to the periphery of the probe. There was a gap on the lapped interface under the probe (Figure 8(a)). However, the bonding area encompassed through the lapped interface under the probe for AS and GA (Figure 8(b)). The melting temperature of ZAM and GI was lower than welding temperature of the present FSSW. The plated layer would melt, so a thin liquid film of the plated layer possibly formed under the probe, which could prevent direct contact of aluminum and steel surface. The thin liquid film would solidify and form shrinkage cavity with a decrease of temperature. However, AS and GA, of which the melting temperature of plated layer was higher than welding temperature, had different phenomenon.

The common metallurgical zones on the cross-sections of FSSW weld are hooking, partial bonding, and bonding ligament (Figure 9). The hooking had a shape of an upside down V; the partial bonding was a transition region where the bonding between upper and lower sheet was not so strong, and it was a short and uneven line on the joint cross-section; the bonding ligament presented banded structure due to materials flow and the penetration force in the joint $[11,27]$. Shen et al. explained banded structure to entrapment of alclad into the joint, when the lower sheet flowed upward [28]. Many persons have investigated hooking feature originating from the faying surface of the two sheets $[24,28,29]$. Yuan et al. [24] attributed it to the uncompleted break-up of aluminum oxide film. Other persons explained it to poor flowability of materials and insufficient pressure [28]. Badarinarayan et al. [29] showed that the hooking made with cylindrical pin ran gradually upward, while the hook made with triangular pin ended near SZ.

Another common defect that could be seen in weld is void. For the refill FSSW joint of 6061-T4 alloy, Shen et al. [27] 

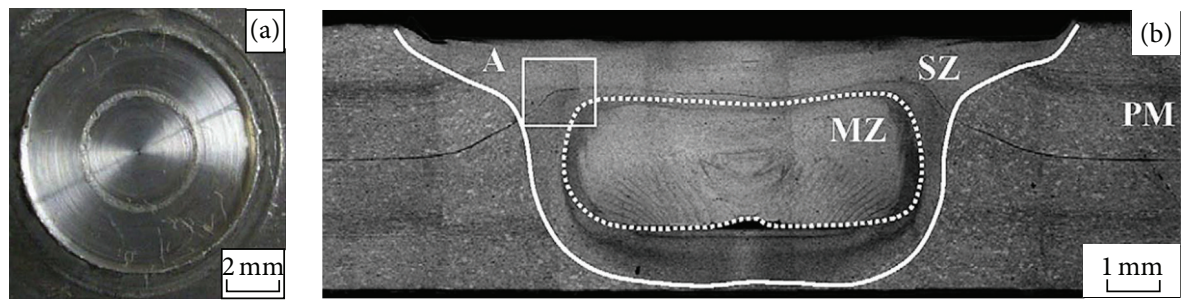

FIGURE 7: Macroscopic appearance of a FSSW joint with refilled probe hole: (a) top view of weld zone and (b) cross-section of weld zone [20].

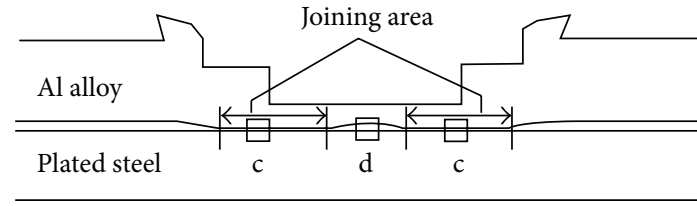

(a)

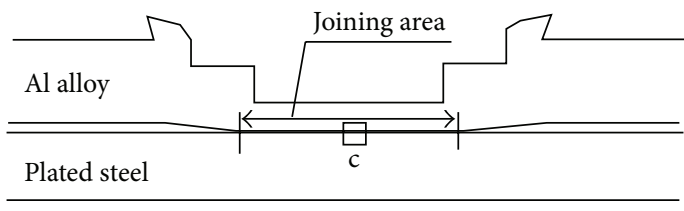

(b)

FIGURE 8: Schematic illustration of the joint interface: (a) ZAM and GI, (b) AS and GA [26].

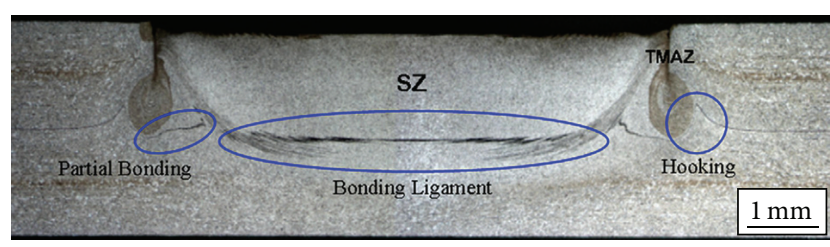

FIGURE 9: OM macrograph of a typical FSSW joint cross-section [11].

found that voids, which were owing to insufficient material flow, were formed on the hooking and the path through which the sleeve plunges into the sheet. Other persons explained it to thermal shrinkage, entrapped air, or some physicalchemical reactions [30].

3.2. Microstructure of FSSW Joints. Under friction heat and stirring, SZ presented fine equiaxed grains due to recrystallisation $[15,18,19,31]$. Sizes of grains in SZ increased with the increase of rotation speed [31]. The grains of SZ were influenced by the shape of tool. It was concluded that the triangular pin resulted in finer grain than the cylindrical pin $[29,32]$. Sun et al. [15] reported that SZ had low dislocation density because of recrystallization. In the entire SZ of AZ31 and AM60 welds, Yamamoto et al. [33] observed fine equiaxed a-Mg grains which had diameters $<10 \mu \mathrm{m}$. Shen et al. [28] investigated refill FSSW of AA7075, the hardening precipitates of SZ were dissolved and broken into particles by stirring of the tool. The grains in the boundary of the pin and sleeve were finer than those in the center because the materials in boundary were stirred more severely than other regions.

TMAZ experienced both frictional heat and deformation which resulted in highly deformed grains [31]. Recrystallization was not observed in TMAZ of AA7075 refill FSSW due to insufficient deformation strain [28]. The heating rate of FSSW was rapid, which limited the dissolution of secondphase particle in TMAZ [34]. Hence Yin et al. [34] observed
$\alpha$-Mg grains for AZ31 weld. Similar phenomenon has been found in AZ91 weld [35].

The HAZ only experienced a welding thermal cycle, which caused the coarser grains [35]. For the refill FSSW joint of AA7075, HAZ had coarser strengthening precipitates than those in the BM [28].

For the new FSSW technique used by Sun et al. $[15,16]$, when the rotation speed was lower than $700 \mathrm{rpm}$ in the first step, only one SZ and TMAZ could be found after the second step. However, when the rotation speed was higher than $700 \mathrm{rpm}$ in the first step, the SZ and TMAZ that formed in first step could be overlapped by those that formed in the second step. Two kinds of SZ and TMAZ could be seen in the weld after the second step.

Yin et al. [36] reported that SZ of AZ91-AZ31 FSSW weld contained dissimilar intermingled AZ31 and AZ91 lamellae, which had similar chemical compositions with those of the AZ31 and AZ91 sheet materials prior to spot welding. Also, diffusion of aluminum at boundaries of AZ91 and AZ31 could be seen by EDS [36]. Diffusion of the solute has also been reported in weld of Al5754-Al6111 [37].

\section{Property of FSSW Joints}

4.1. Tensile-Shear Strength of FSSW Joints. In tensile-shear tests, shims of the same material and thickness as the sample were used when clamping the samples to induce pure shear [11]. There are usually two samples: tensile-shear and crosstension specimens. Yuan et al. [24] indicated that the rotation speed and plunge depth were the main influence factors for tensile-shear strength. Zhang et al. [31] reported that joint strength was mainly decided by rotation speed while it was not affected significantly by dwell time. While Lin et al. [38] reported the different phenomenon, in their study, experimental results showed that the rotation speed and dwell time were dominant factors for tensile-shear strength. Strength of specimens increased as dwell time increased, which was related to growth of grains. A similar phenomenon has 
been observed in polyethylene sheets [39] and 5754-O/7075T6 joints [40]. Optimal welding parameters will improve the weld strength. The improvement in the weld strength from the initial welding parameters to the optimal welding parameters was about $47.7 \%$ for high density polypropylene [41].

For the cross-tension sample, the tensile-shear strength was affected by rotation speed, while dwell time had less influence on strength. The weld strength reached the maximum $902.1 \mathrm{~N}$ [31]. Badarinarayan et al. [29, 32] reported that crosstension sample had the same results with tensile-shear sample in tensile-shear tests.

Tozaki et al. [1] investigated tensile-shear sample of AA6061-T4 in pinless FSSW. It was indicated that the thickness of the upper sheet underneath the shoulder indentation $(t)$ and the actual nugget size $(d)$ were two significant geometrical parameters which determined the tensile-shear strength of the welds. The $d$ size increased with increasing of tool rotation speed and dwell time. Under tensile-shear loading, the increase in the $d$ size resulted in the increase of the tensile-shear strength because of increased effective area $[42,43]$. For cross-tension sample, $t$ dominated the weld strength. The size of $t$ decreased with increasing of dwell time and tool rotation speed. Hence, the cross-tension strength decreased correspondingly [42]. AA6061 had similar results [43]. For alloy refill FSSW joints of AZ31 magnesium, tensileshear strength of welds depended on the hook morphology and friction input [44].

Morphology of the tool has influence on the weld. Badarinarayan et al. $[29,32]$ indicated that strength of weld made with the triangular pin was twice than that of weld made with the cylindrical pin, which was attributed to the grain size as well as tensile failure mode. Choi et al. [45] compared tensile-shear strength of 5J32 Al alloy FSSW weld under three tool shapes (threaded pin tool: TPT; cylindrical tool: CT; cylindrical tool with projection: CTP). The results showed that projection of CTP retarded the vertical joint deformation; hence the tensile-shear strength rapidly increased with increasing of tool plunge depth. For TPT and $\mathrm{CT}$, the tensile-shear strength of the joint did not increase because of the decrease of the upper plate thickness, which decreased with the increase of plunge depth. The maximum strength for CTP was about $4600 \mathrm{~N}$, which was higher than that in other two tool shapes [45]. Bilici and Yükler [39] reported that the joint strength changed with the change of concavity angle. The maximum strength was obtained at $6^{\circ}$ shoulder concavity angle.

For FSSW weld of dissimilar materials, the variations of weld strength depended on the material positioned on the upper side of the specimen configuration [40,46, 47]. In the cases of dissimilar FSSW between a bulk metallic glass alloy and crystalline alloy, when the crystalline metal was positioned on the upper side, it showed a higher fracture load as compared with the opposite $[46,47]$.

In tensile-shear tests, there are usually three different separation modes: interfacial shear separation, nugget pullout separation, and upper or lower sheet fracture separation. The joint with nugget fracture separation had higher strength [48]. For tensile-shear sample, cracks of interfacial shear separation initiated preferentially at the crack tip in a weld and propagated along the bonded interface [38]. For the nugget pull-out separation, two sheets tended to get separated at the partial bonding under loading. This separation led to the formation of an annular crack surrounding the SZ, which resulted in the decrease of effective shear area of the joint. It was indicated that circumferential cracks would nucleate on just one or both sheets. On the upper sheet, the only two nucleation sites observed were the hooking tip and the welding defects, while it initiated at the interface between the partial bonding and the hooking on the lower sheet [11]. Separation modes mainly depended on the area of SZ [40]. Tozaki et al. [42] investigated the separation mode of both tensile-shear and cross-tension specimens. Results showed that final fracture modes were related to the thickness of the upper sheet at the outer circumference of the shoulder indentation $(t)$ [42].

Prakash and Muthukumaran [49] investigated refill FSSW of Al-Mg-Si aluminum, in the study, joint that had higher strength than the joint made by conversational FSSW because refilling process increased effective cross-sectional area of the nugget. Uematsu et al. [20] also reported that refilling process improved tensile strength by about $30 \%$. Many persons demonstrated that weld made with pinless tool had higher strength than that made with conventional tool [1, 13, 50-52]. While Cox et al. [12] reported that tensile strength of welds made with a pinless tool was on average $90 \%$ of conventional FSSW, for swing FSSW, Yan et al. [21] showed that tensile strength increased by about $40 \%$ compared to conventional FSSW.

Zhang et al. [31] applied the tool to move a distance of about $5 \mathrm{~mm}$ along the width direction and left a complete weld about $5 \mathrm{~mm}$ in length, which was called walking FSSW. Compared to conversational FSSW, the strength of the joints welded by walking FSSW improved a little. In tensile-shear tests, for both tensile-shear and cross-tensile samples, nugget debonding first took place near the keyhole and then the crack propagated towards the walking side, causing the whole nugget in the walking side to pull out [31].

4.2. Fatigue Strength of FSSW Joints. The fatigue cracks were observed to propagate through the tip of hooking [53]. There are also usually two samples: lap-shear and crosstension specimens. The fractography analysis suggested that the effective top sheet thickness, interfacial hooking, and microstructure significantly affected the fatigue behavior of the friction stir spot welds in magnesium alloys [54]. In the similar welds, fracture mode was irrelevant to load levels for lap-shear specimens, and crack took place in lower sheet under high or low load levels $[55,56]$. However, the fatigue modes of FSSW in AZ31 depended on the cyclic load amplitude $[53,57]$. Nugget pullout took place under high load amplitude, while crack propagated along width of samples under low load amplitude [53]. Similarly, Tran et al. [58] investigated failure modes of the 5754 and 6111 similar welds. Result showed that under quasistatic loading conditions, welds mainly failed from the nearly flat fracture surface through the nugget. Under low-cycle loading conditions, 
both types of welds mainly failed through the upper sheet thickness. Under high-cycle loading conditions, both types of welds mainly failed through the upper and lower sheet thicknesses [58].

For A6061 and low carbon steel sheets dissimilar lapshear welds, fatigue fracture modes were dependent on fatigue load level. Shear fracture through the interface occurred at high load levels, and a fatigue crack grew through the upper sheet at low load levels [55, 56]. Tran et al. [59] investigated that failure mode of the 5754-7075 welds in lapshear specimens, under quasistatic loading conditions, crack propagated along the nugget circumference, under cyclic loading conditions, crack propagated in the width direction of the specimen, and the left part of the lower sheet was eventually separated (Figure 10). A similar phenomenon took place in AZ31B-H24 Mg alloy and 5754-O Al alloy dissimilar lap-shear welds; in the (top) Al-Mg (bottom) with an adhesive interlayer weld, nugget pull-out failure occurred at high cyclic loads. At low cyclic loads, fatigue failure occurred in the bottom $\mathrm{Mg}$ sheet. For (top) Mg-Al (bottom) with an adhesive interlayer weld, nugget pull-out failure modes were observed at both high and low cyclic loads [61]. The fatigue cracks between Al-steel and $\mathrm{Mg}$-steel welds grew through the interface dominantly [57]. The results were similar to the results of $\mathrm{Mg}-\mathrm{Al}$ in [61].

For cross-tension specimen, Lin et al. [60] investigated the failure modes in FSSW of aluminum 6061-T6 sheets. In their study, there were two different nugget pull-out failure modes (Figure 11). Under quasistatic and low-cycle loading conditions, the upper nugget was pulled out, while the lower nugget was pulled out under high-cycle loading [60]. For 5754-7075 welds in cross-tension specimens, Tran et al. [59] reported that under quasistatic loading conditions, crack propagated through the upper sheet thickness; under cyclic loading conditions, crack propagated along the interfacial surface in the downward direction toward the central hole.

Hassanifard et al. [62] introduced a new method for enhancing the life and fatigue strength of friction stir spot weld in Al alloy 7075-T6. This method had two steps, in the first step, a keyhole in the middle of joints was transferred to open hole by means of drilling; in the second step, the open hole samples were allocated for cold expansion process in order to induce compressive residual stresses. The results showed that the cold expansion could enhance the fatigue life of joints without altering their failure modes [62].

Uematsu et al. [20] reported that the fatigue strength of the refill FSSW was lower than that of the joint with probe hole at low and high applied loads. At high applied loads, the authors explained it to the difference of fracture mode between refill FSSW and conversational FSSW [20].

\section{Modelling of the FSSW Process}

To optimise the process parameters and develop FSSW new tools, it is important to understand the physics of this complex process that involves fatigue life, temperature gradient, and strength by numerical simulation [63]. Wang and Chen [64] developed a fatigue crack growth model based on the Paris law and the local stress intensity factors to predict the fatigue lives of aluminum 6061-T6 lap-shear welds; the results agreed well with the experimental results. Lin et al. [60] got the similar results. Moreover, modelling conducted in AZ31 alloy lap-shear welds suggested that the size of the interfacial hook was a major influence on the fatigue life of the joint [63].

For the friction heat, Awang and Mucino [65] used Johnson-Cook material model to analyze energy generation of FSSW of 6061-T6 aluminum alloy. The results suggested that the peak temperature at the tip of the pin and frictional dissipation energy were in agreement with the experimental work done by Gerlich et al. [66]. The difference was about $5.1 \%$. Friction heat at the interface of the tool and the workpiece generated the most energy, which was about $96.84 \%$; rotational speed and plunge rate also had a significant effect on frictional dissipation energy [65].

In order to optimize welding parameters of FSSW and increase strength of welds, Atharifar [67] used artificial neural network to optimize welding parameters. This network was designed with three process parameters as inputs and three process variables as outputs. The outputs were selected as the weld's tensile strength, plunging load, and dwell time. Results suggested that the obtained optimums of the FSSW parameters were valid, and the welds with higher weld strength, lower plunging load, and shorter dwell time were gained by utilizing these parameters [67]. Kulekci et al. [68] compared the factorial design and neural network. Neural network was better than factorial design technique for the predicting of the tensile-shear strength in 5005 aluminum alloys. Moreover, regression analysis method was used to analyse the relation between the tensile-shear strength and FSSW welding parameters, and pin height was found to be the major factor for tensile-shear strength of FSSW joints [68]. However, Karthikeyan and Balasubramanian [69] reported that plunge rate had greater influence on tensileshear strength. The authors also developed an empirical relationship to predict the tensile-shear strength of AA2024T3 aluminum alloy FSSW joints and applied response surface methodology to attain maximum tensile-shear strength of welds.

Kim et al. [70] utilized two ways to develop thermomechanical simulations of AA5083-H18 and AA6022-T4. The two methods were commercial finite element method (FEM) based on Lagrangian and finite volume method (FVM) based on Eulerian formulations. The effect of pin geometry on weld strength and material flow was understood by simulation [70].

For the refill FSSW, Muci-Küchler et al. [63] presented a fully coupled thermomechanical finite element model to predict the temperature, deformation, stress, and strain distributions in the joints. The simulation results were in good agreement with experimental studies [63]. Hooking will degrade the joint properties. In order to reveal the formation mechanism of hooking during pinless FSSW, Zhang et al. [71] developed a 3D fully coupled thermomechanical FE model; the results showed that the hook formation could be mainly attributed to the difference of material flow in different weld zones. 


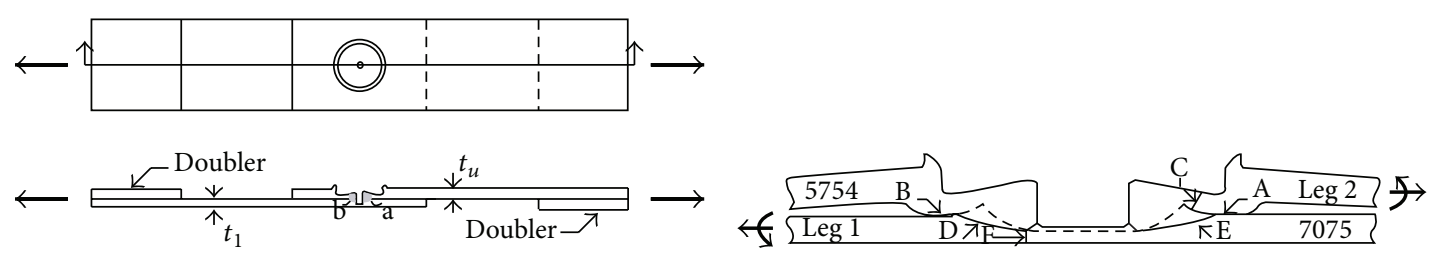

(a)

(b)

\begin{tabular}{|c|c|}
\hline & \multicolumn{1}{|c|}{ Failure mode } \\
\hline Quasistatic & $\mathrm{A}, \mathrm{B} \rightarrow \mathrm{C} \rightarrow$ circumferential crack $\rightarrow \mathrm{D} \rightarrow \mathrm{E}$ \\
\hline Cyclic & $\mathrm{A}, \mathrm{B} \rightarrow \mathrm{D} \rightarrow \mathrm{F} \rightarrow$ transverse through crack \\
\hline
\end{tabular}

(c)

FIGURE 10: (a) Schematic plots of a spot friction weld in a lap-shear specimen under applied resultant loads (shown as the bold arrows), (b) a schematic plot of the cross-section along the symmetry plane of a 5754-7075 weld in a lap-shear specimen, and (c) failure modes of the 5754-7075 welds in lap-shear specimens under quasistatic and cyclic loading conditions [59].

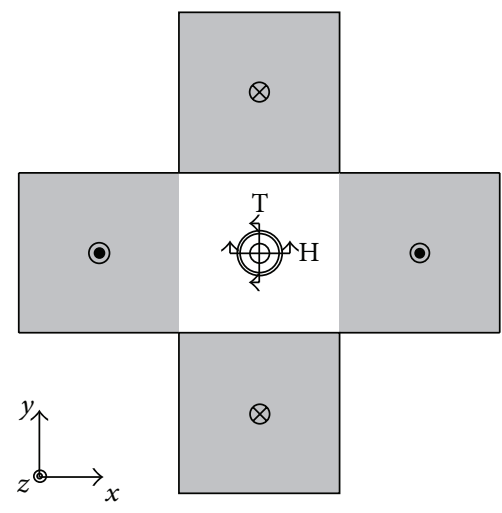

(a)

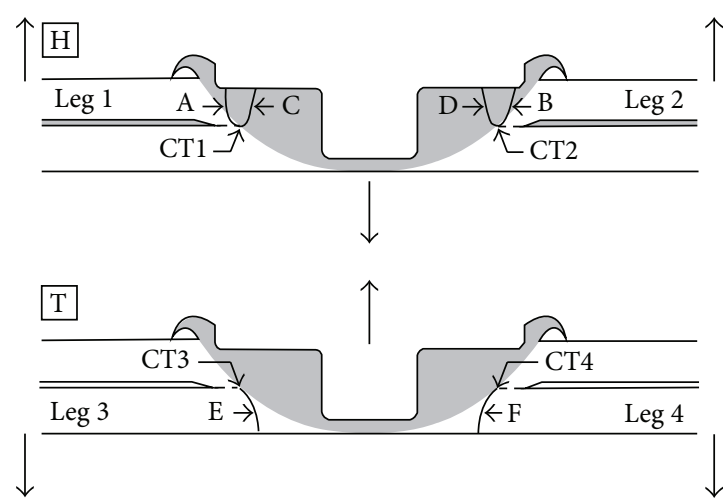

(b)

\begin{tabular}{|l|l|}
\hline & \multicolumn{1}{|c|}{ Failure mode } \\
\hline Quasistatic & $\mathrm{A}, \mathrm{B} \rightarrow$ circumferential cracks $\rightarrow$ upper nugget pullout \\
\hline Low cycle & $\mathrm{C}, \mathrm{D} \rightarrow$ circumferential cracks $\rightarrow$ upper nugget pullout \\
& $\mathrm{E}, \mathrm{F} \rightarrow$ \\
\hline High cycle & $\mathrm{C}, \mathrm{D} \rightarrow$ \\
& $\mathrm{E}, \mathrm{F} \rightarrow$ circumferential cracks $\rightarrow$ lower nugget pullout \\
\hline
\end{tabular}

(c)

FIGURE 11: Schematics of (a) the top view of a cross-tension specimen, (b) the cross-sections along the horizontal (marked by $\mathrm{H}$ ) and transverse (marked by T) symmetry planes of the spot friction weld, respectively, and (c) the failure modes of spot friction welds under different loading conditions [60].

\section{Summary and Perspectives}

At present, the FSSW process has become one of the most optimal processes in substituting the conventional resistance spot welding and riveting in joining lightweight structural metals, such as aluminum and magnesium alloys, in the automotive and aerospace industries.

FSSW could be classified into four types: conventional FSSW, refill FSSW, pinless FSSW, and swing FSSW. Normally, three distinct regions are observed in the FSSW joints: the stir zone (SZ), the thermomechanically affected zone (TMAZ), and the heat affected zone (HAZ). In tensile-shear tests, there are usually three different failure modes: interfacial shear separation, nugget pull-out separation, and upper or lower sheet fracture separation. The fatigue cracks usually propagate through the tip of hooking. However, there are still no mature theory and abundant database for applications of FSSW. Reliability of joints has not been understood totally. To the authors' knowledge, there are still important issues that need to be revealed.

(1) FSSW techniques without keyhole defect (refill FSSW, pinless FSSW, and other new processes) should be paid more attention.

(2) The materials used in FSSW should be enlarged. Besides aluminum and magnesium alloys, engineering plastics and other materials also need to be introduced into the research scope.

(3) The flexible, multipurpose, and reliable FSSW equipment should be developed for better applications in industrial production. 


\section{Conflict of Interests}

The authors declare that they do not have a direct relation with any commercial identities that might lead to a conflict of interests for any of them.

\section{Acknowledgments}

The authors would like to appreciate financial supports from the Fok Ying-Tong Education Foundation for Young Teachers in the Higher Education Institutions of China (131052), the Fundamental Research Fund of NPU (JC201233), and the 111 Project (B08040).

\section{References}

[1] Y. Tozaki, Y. Uematsu, and K. Tokaji, "A newly developed tool without probe for friction stir spot welding and its performance," Journal of Materials Processing Technology, vol. 210, no. 6-7, pp. 844-851, 2010.

[2] N. Nguyen, D. Y. Kim, and H. Y. Kim, "Assessment of the failure load for an AA6061-T6 friction stir spot welding joint," Proceedings of the Institution of Mechanical Engineers, Part B: Journal of Engineering Manufacture, vol. 225, no. 10, pp. 17461756, 2011.

[3] W. M. Thomas, E. D. Nicholas, and J. C. Needham, "Friction stir welding," International patent PCT/GB92102203 and Great Britain patent 9125978.8, 1991.

[4] R. S. Mishra and Z. Y. Ma, "Friction stir welding and processing," Materials Science and Engineering, vol. 50, no. 1-2, pp. 1-78, 2005.

[5] C. J. Dawes, "An introduction to friction stir welding and its development," Welding and Metal Fabrication, vol. 63, no. 1, pp. 12-16, 1995.

[6] C. G. Rhodes, M. W. Mahoney, W. H. Bingel, R. A. Spurling, and C. C. Bampton, "Effects of friction stir welding on microstructure of 7075 aluminum," Scripta Materialia, vol. 36, no. 1, pp. 69-75, 1997.

[7] C. J. Dawes and W. M. Thomas, "Friction stir process welds aluminium alloys: the process produces low-distortion, highquality, low-cost welds on aluminium," Welding Journal, vol. 75, no. 3, pp. 41-45, 1996.

[8] R. Sakano, K. Murakami, K. Yamashita et al., "Development of spot FSW robot system for automobile body members," in Proceedings of the 3rd International Symposium of Friction Stir Welding, Kobe, Japan, 2004.

[9] N.-T. Nguyen, D.-Y. Kim, and H. Y. Kim, "Assessment of the failure load for an AA6061-T6 friction stir spot welding joint," Proceedings of the Institution of Mechanical Engineers B: Journal of Engineering Manufacture, vol. 225, no. 10, pp. 1746-1756, 2011.

[10] C. Schilling and J. Dos Santos, "Method and device for linking at least two adjoining work pieces by friction welding," US Patent 6722556B2, 2004.

[11] T. Rosendo, B. Parra, M. A. D. Tier et al., "Mechanical and microstructural investigation of friction spot welded AA6181T4 aluminium alloy," Materials and Design, vol. 32, no. 3, pp. 1094-1100, 2011.

[12] C. D. Cox, B. T. Gibson, A. M. Strauss, and G. E. Cook, "Effect of pin length and rotation rate on the tensile strength of a friction stir spot-welded al alloy: A contribution to automated production," Materials and Manufacturing Processes, vol. 27, no. 4, pp. 472-478, 2012.

[13] P. B. Prangnell and D. Bakavos, "Novel approaches to friction spot welding thin aluminium automotive sheet," Materials Science Forum, vol. 638-642, pp. 1237-1242, 2010.

[14] Y. Fang, The Research on the Processes and Proprerties of Pinless Friction Stir Spot Welding, Jiangsu University of Science and Technology, Jiangsu, China, 2009.

[15] Y. F. Sun, H. Fujii, N. Takaki, and Y. Okitsu, "Microstructure and mechanical properties of mild steel joints prepared by a flat friction stir spot welding technique," Materials \& Design, vol. 37, pp. 384-392, 2012.

[16] Y. F. Sun, H. Fujii, N. Takaki, and Y. Okitsu, "Novel spot friction stir welding of 6061 and $5052 \mathrm{Al}$ alloys," Science and Technology of Welding and Joining, vol. 16, no. 7, pp. 605-612, 2011.

[17] Y. F. Sun, H. Fujii, N. Takaki, and Y. Okitsu, "Microstructure and mechanical properties of dissimilar $\mathrm{Al}$ alloy/steel joints prepared by a flat spot friction stir welding technique," Materials and Design, vol. 47, pp. 350-357, 2013.

[18] D.-A. Wang and S.-C. Lee, "Microstructures and failure mechanisms of friction stir spot welds of aluminum 6061-T6 sheets," Journal of Materials Processing Technology, vol. 186, no. 1-3, pp. 291-297, 2007.

[19] D. Wang, C. Chao, P. Lin, and J. Uan, "Mechanical characterization of friction stir spot microwelds," Journal of Materials Processing Technology, vol. 210, no. 14, pp. 1942-1948, 2010.

[20] Y. Uematsu, K. Tokaji, Y. Tozaki, T. Kurita, and S. Murata, "Effect of re-filling probe hole on tensile failure and fatigue behaviour of friction stir spot welded joints in Al-Mg-Si alloy," International Journal of Fatigue, vol. 30, no. 10-11, pp. 1956-1966, 2008 .

[21] K. Yan, Z. Y. Li, and J. Fu, "The metal flow behavior of swing friction stir spot welding joint," Journal of Jiangsu University of Science and Technology, vol. 22, no. 2, pp. 35-38, 2008.

[22] M. Fujimoto, M. Inuzuka, S. Koga, and Y. Seta, "Development of friction spot joining," Welding in the World, vol. 49, no. 3-4, pp. 18-21, 2005.

[23] S. Baek, D. Choi, C. Lee et al., "Microstructure and mechanical properties of friction stir spot welded galvanized steel," Materials Transactions, vol. 51, no. 5, pp. 1044-1050, 2010.

[24] W. Yuan, R. S. Mishra, S. Webb et al., "Effect of tool design and process parameters on properties of Al alloy 6016 friction stir spot welds," Journal of Materials Processing Technology, vol. 211, no. 6, pp. 972-977, 2011.

[25] W. Y. Li, J. F. Li, D. L. Gao et al., "Pinless friction stir spot welding of 2024 aluminum alloy: effect of welding parameters," in Proceedings of the 7th Asia Pacific IIW International Congress, pp. 72-77, 2013.

[26] K. Feng, M. Watanabe, and S. Kumai, "Microstructure and joint strength of friction stir spot welded 6022 aluminum alloy sheets and plated steel sheets," Materials Transactions, vol. 52, no. 7, pp. 1418-1425, 2011.

[27] Z. Shen, X. Yang, S. Yang et al., "Microstructure and mechanical properties of friction spot welded 6061-T4 aluminum alloy," Materials and Design, vol. 54, pp. 766-778, 2014.

[28] Z. Shen, X. Yang, Z. Zhang, L. Cui, and T. Li, "Microstructure and failure mechanisms of refill friction stir spot welded 7075T6 aluminum alloy joints," Materials and Design, vol. 44, pp. 476-486, 2013

[29] H. Badarinarayan, Q. Yang, and S. Zhu, "Effect of tool geometry on static strength of friction stir spot-welded aluminum alloy," 
International Journal of Machine Tools and Manufacture, vol. 49, no. 2, pp. 142-148, 2009.

[30] P. H. F. Oliveira, S. T. Amancio-Filho, J. F. Dos Santos, and E. Hage Jr., "Preliminary study on the feasibility of friction spot welding in PMMA," Materials Letters, vol. 64, no. 19, pp. 20982101, 2010.

[31] Z. H. Zhang, X. Q. Yang, J. L. Zhang, G. Zhou, X. Xu, and B. Zou, "Effect of welding parameters on microstructure and mechanical properties of friction stir spot welded 5052 aluminum alloy," Materials \& Design, vol. 32, no. 8-9, pp. 44614470, 2011.

[32] H. Badarinarayan, Y. Shi, X. Li, and K. Okamoto, "Effect of tool geometry on hook formation and static strength of friction stir spot welded aluminum 5754-O sheets," International Journal of Machine Tools and Manufacture, vol. 49, no. 11, pp. 814-823, 2009.

[33] M. Yamamoto, A. Gerlich, T. H. North, and K. Shinozaki, "Cracking in the stir zones of Mg-alloy friction stir spot welds," Journal of Materials Science, vol. 42, no. 18, pp. 7657-7666, 2007.

[34] Y. H. Yin, A. Ikuta, and T. H. North, "Microstructural features and mechanical properties of AM60 and AZ31 friction stir spot welds," Materials and Design, vol. 31, no. 10, pp. 4764-4776, 2010.

[35] M. Yamamoto, A. Gerlich, T. H. North, and K. Shinozaki, "Cracking in dissimilar Mg alloy friction stir spot welds," Science and Technology of Welding and Joining, vol. 13, no. 7, pp. 583-592, 2008.

[36] Y. H. Yin, N. Sun, T. H. North, and S. S. Hu, "Microstructures and mechanical properties in dissimilar AZ91/AZ31 spot welds," Materials Characterization, vol. 61, no. 10, pp. 1018-1028, 2010.

[37] P. Su, A. Gerlich, T. H. North, and G. J. Bendzsak, "Intermixing in dissimilar friction stir spot welds," Metallurgical and Materials Transactions A, vol. 38, no. 3, pp. 584-595, 2007.

[38] Y. C. Liu, J. J. Lin, B. Y. Lin, C. M. Lin, and H. L. Tsai, "Effects of process parameters on strength of Mg alloy AZ61 friction stir spot welds," Materials and Design, vol. 35, pp. 350-357, 2012.

[39] M. K. Bilici and A. I. Yükler, "Influence of tool geometry and process parameters on macrostructure and static strength in friction stir spot welded polyethylene sheets," Materials and Design, vol. 33, no. 1, pp. 145-152, 2012.

[40] V. X. Tran, J. Pan, and T. Pan, "Effects of processing time on strengths and failure modes of dissimilar spot friction welds between aluminum 5754-O and 7075-T6 sheets," Journal of Materials Processing Technology, vol. 209, no. 8, pp. 3724-3739, 2009.

[41] M. K. Bilici, "Application of Taguchi approach to optimize friction stir spot welding parameters of polypropylene," Materials and Design, vol. 35, pp. 113-119, 2012.

[42] Y. Tozaki, Y. Uematsu, and K. Tokaji, "Effect of processing parameters on static strength of dissimilar friction stir spot welds between different aluminium alloys," Fatigue and Fracture of Engineering Materials and Structures, vol. 30, no. 2, pp. 143$148,2007$.

[43] Y. Tozaki, Y. Uematsu, and K. Tokaji, "Effect of tool geometry on microstructure and static strength in friction stir spot welded aluminium alloys," International Journal of Machine Tools and Manufacture, vol. 47, no. 15, pp. 2230-2236, 2007.

[44] L. C. Campanelli, U. F. H. Suhuddin, A. Í. S. Antonialli, J. F. dos Santos, N. G. de Alcântara, and C. Bolfarini, "Metallurgy and mechanical performance of AZ31 magnesium alloy friction spot welds," Journal of Materials Processing Technology, vol. 213, no. 4, pp. 515-521, 2013.
[45] D. H. Choi, B. W. Ahn, C. Y. Lee, Y. M. Yeon, and K. B. Song, "Effect of pin shapes on joint characteristics of friction stir spot welded AA5J32 sheet," Materials Transactions, vol. 51, no. 5, pp. 1028-1032, 2010.

[46] H. Shin and Y. Jung, "Characteristics of dissimilar friction stir spot welding of bulk metallic glass to lightweight crystalline metals," Intermetallics, vol. 18, no. 10, pp. 2000-2004, 2010.

[47] H. Shin and Y. Jung, "Characteristics of friction stir spot welding of Zr-based bulk metallic glass sheets," Journal of Alloys and Compounds, vol. 504, no. 1, pp. S279-S282, 2010.

[48] M. K. Bilici and A. I. Yukler, "Effects of welding parameters on friction stir spot welding of high density polyethylene sheets," Materials and Design, vol. 33, no. 1, pp. 545-550, 2012.

[49] S. J. Prakash and S. Muthukumaran, "Refilling probe hole of friction spot joints by friction forming," Materials and Manufacturing Processes, vol. 26, no. 12, pp. 1539-1545, 2011.

[50] M. Simoncini and A. Forcellese, "Effect of the welding parameters and tool configuration on micro- and macro-mechanical properties of similar and dissimilar FSWed joints in AA5754 and AZ31 thin sheets," Materials \& Design, vol. 41, pp. 50-60, 2012.

[51] A. Forcellese, F. Gabrielli, and M. Simoncini, "Mechanical properties and microstructure of joints in AZ31 thin sheets obtained by friction stir welding using "pin" and "pinless" tool configurations," Materials and Design, vol. 34, pp. 219-229, 2012.

[52] D. Bakavos and P. B. Prangnell, "Effect of reduced or zero pin length and anvil insulation on friction stir spot welding thin gauge 6111 automotive sheet," Science and Technology of Welding and Joining, vol. 14, no. 5, pp. 443-456, 2009.

[53] J. B. Jordon, M. F. Horstemeyer, S. R. Daniewicz, H. Badarinarayan, and J. Grantham, "Fatigue characterization and modeling of friction stir spot welds in magnesium AZ31 alloy," Journal of Engineering Materials and Technology, Transactions of the ASME, vol. 132, no. 4, Article ID 041008, 2010.

[54] H. M. Rao, J. B. Jordon, M. E. Barkey, Y. B. Guo, X. Su, and $\mathrm{H}$. Badarinarayan, "Influence of structural integrity on fatigue behavior of friction stir spot welded AZ31 Mg alloy," Materials Science and Engineering A, vol. 564, pp. 369-380, 2013.

[55] . Y Uematsu, K. Tokaji, and Y. Tozaki, "Fatigue behaviour of dissimilar friction stir spot weld between A6061 and SPCC welded by a scrolled groove shoulder tool," Procedia Engineering, vol. 2, no. 1, pp. 193-201, 2010.

[56] Y. Uematsu, K. Tokaji, Y. Tozaki, Y. Nakashima, and T. Shimizu, "Fatigue behaviour of dissimilar friction stir spot welds between A6061-T6 and low carbon steel sheets welded by a scroll grooved tool without probe," Fatigue and Fracture of Engineering Materials and Structures, vol. 34, no. 8, pp. 581-591, 2011.

[57] Y. Uematsu, T. Kakiuchi, Y. Tozaki, and H. Kojin, "Comparative study of fatigue behaviour in dissimilar $\mathrm{Al}$ alloy/steel and $\mathrm{Mg}$ alloy/steel friction stir spot welds fabricated by scroll grooved tool without probe," Science and Technology of Welding and Joining, vol. 17, no. 5, pp. 348-356, 2012.

[58] V.-X. Tran, J. Pan, and T. Pan, "Fatigue behavior of aluminum 5754-O and 6111-T4 spot friction welds in lap-shear specimens," International Journal of Fatigue, vol. 30, no. 12, pp. 2175-2190, 2008.

[59] V. X. Tran, J. Pan, and T. Pan, "Fatigue behavior of spot friction welds in lap-shear and cross-tension specimens of dissimilar aluminum sheets," International Journal of Fatigue, vol. 32, no. 7, pp. 1022-1041, 2010.

[60] P. C. Lin, Z. M. Su, R. Y. He, and Z.-L. Lin, "Failure modes and fatigue life estimations of spot friction welds in cross-tension 
specimens of aluminum 6061-T6 sheets," International Journal of Fatigue, vol. 38, pp. 25-35, 2012.

[61] S. H. Chowdhury, D. L. Chen, S. D. Bhole, X. Cao, and P. Wanjara, "Lap shear strength and fatigue behavior of friction stir spot welded dissimilar magnesium-to-aluminum joints with adhesive," Materials Science and Engineering A, vol. 562, pp. 53-60, 2013.

[62] S. Hassanifard, M. Mohammadpour, and H. A. Rashid, "A novel method for improving fatigue life of friction stir spot welded joints using localized plasticity," Materials and Design, vol. 53, pp. 962-971, 2014.

[63] K. H. Muci-Küchler, S. Kalagara, and W. J. Arbegast, "Simulation of a refill friction stir spot welding process using a fully coupled thermo-mechanical FEM model," Journal of Manufacturing Science and Engineering, Transactions of the ASME, vol. 132, no. 1, Article ID 0145031, 2010.

[64] D. A. Wang and C. H. Chen, "Fatigue lives of friction stir spot welds in aluminum 6061-T6 sheets," Journal of Materials Processing Technology, vol. 209, no. 1, pp. 367-375, 2009.

[65] M. Awang and V. H. Mucino, "Energy generation during friction stir spot welding (FSSW) of Al 6061-T6 plates," Materials and Manufacturing Processes, vol. 25, no. 1-3, pp. 167-174, 2010.

[66] A. Gerlich, P. Su, and T. H. North, "Peak temperatures and microstructures in aluminium and magnesium alloy friction stir spot welds," Science and Technology of Welding and Joining, vol. 10, no. 6, pp. 647-652, 2005.

[67] H. Atharifar, "Optimum parameters design for friction stir spot welding using a genetically optimized neural network system," Proceedings of the Institution of Mechanical Engineers B: Journal of Engineering Manufacture, vol. 224, no. 3, pp. 403-418, 2010.

[68] M. K. Kulekci, U. Esme, O. Er, and Y. Kazancoglu, "Modeling and prediction of weld shear strength in friction stir spot welding using design of experiments and neural network," Materials Science and Engineering Technology, vol. 42, no. 11, pp. 990-995, 2011.

[69] R. Karthikeyan and V. Balasubramanian, "Predictions of the optimized friction stir spot welding process parameters for joining AA2024 aluminum alloy using RSM," The International Journal of Advanced Manufacturing Technology, vol. 51, no. 1-4, pp. 173-183, 2010.

[70] D. Kim, H. Badarinarayan, I. Ryu et al., "Numerical simulation of friction stir spot welding process for aluminum alloys," Metals and Materials International, vol. 16, no. 2, pp. 323-332, 2010.

[71] Z. H. Zhang, W. Y. Li, J. F. Li et al., "Numerical analysis on formation mechanism of hook during pinless friction stir spot welding," in Proceedings of the 7th Asia Pacific IIW International Congress, Singapore, 2013. 

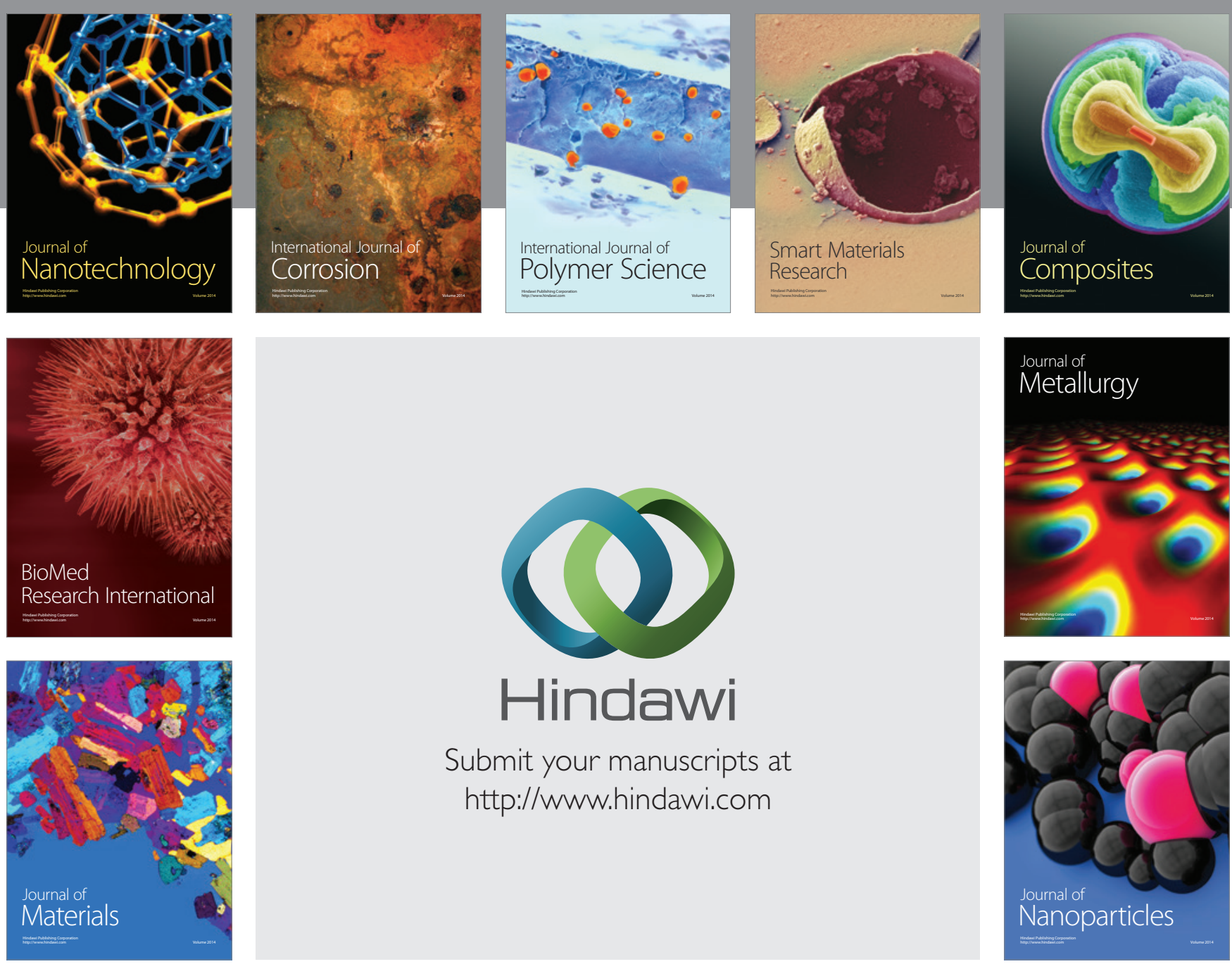

Submit your manuscripts at http://www.hindawi.com
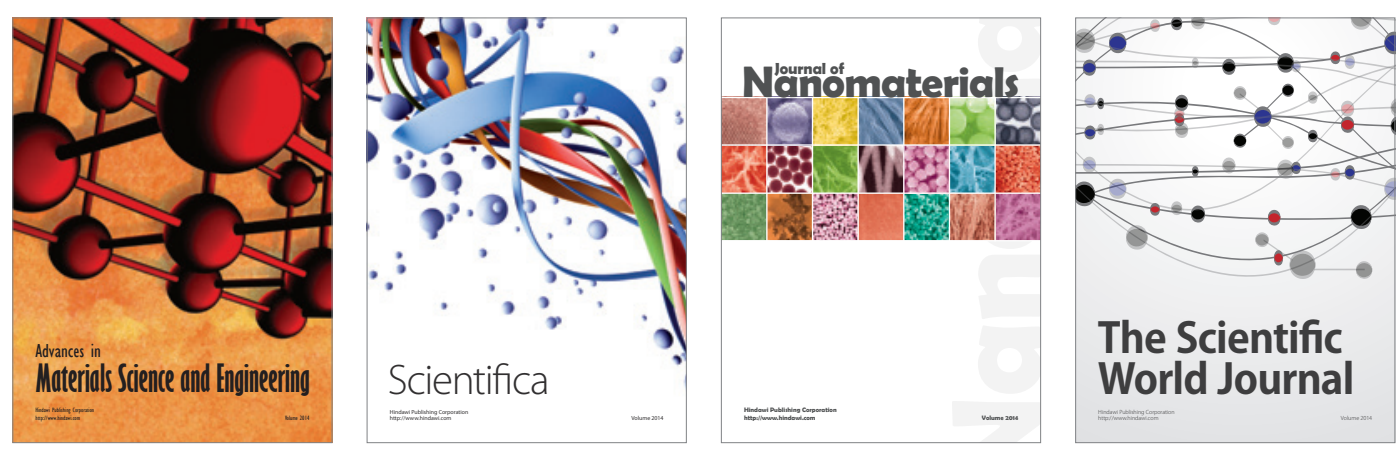

\section{The Scientific World Journal}
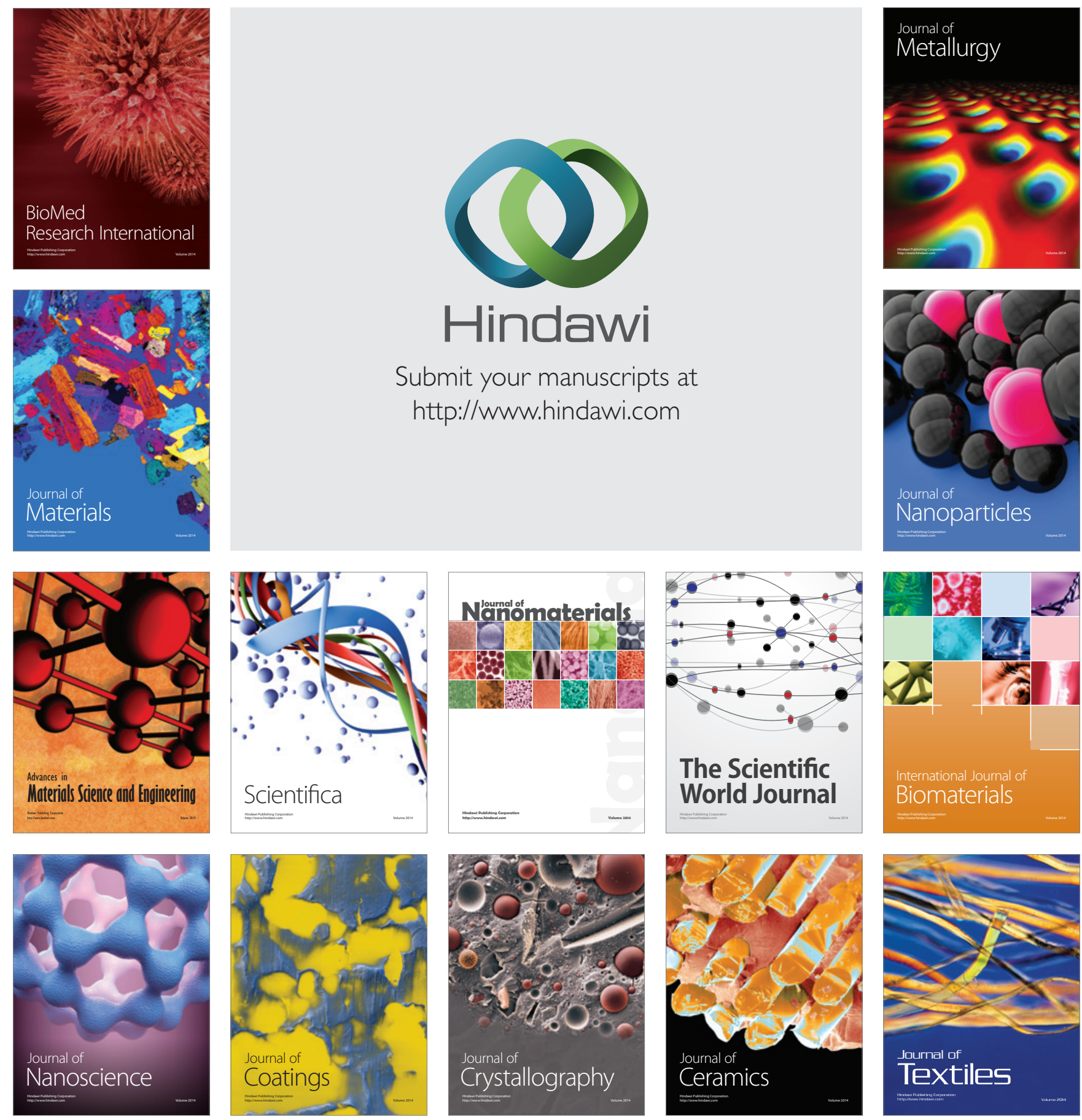